\title{
Plasmodium falciparum-ISOlates FROM CAMEROONIAN PREGNANT WOMEN DO NOT ROSETTE
}

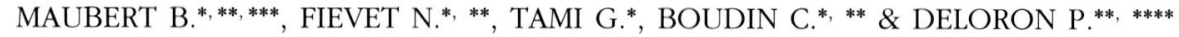

Summary :

The placenta of pregnant women is frequently parasitized by erythrocytes infected by mature stages of Plasmodium falciparum (IE), a phenomenon associated with low birth weight of the offspring. The cytoadherence phenotype of the parasites from pregnant women suggests that placental sequestration may result from cytoadherence to the syncytiotrophoblast. However, as anatomopathological studies report that cytoadherence in the placenta is a rare event, we investigated whether placental parasites may sequester by forming rosettes with uninfected erythrocytes, another possible sequestration mechanism. Parasites from placental blood as well as parasites from the peripheral blood of pregnant and non pregnant subjects were assessed for their ability to rosette. In non pregnant subjects, the rosetting capacity of parasites was as reported in litterature while, except in one case, parasites from pregnant women did not rosette. We conclude that the lack of rosetting is a new feature of IEs from pregnant women and that rosetting cannot be involved in the placental sequestration of IEs.

KEY WORDS : malaria, Plasmodium falciparum, human, placenta, pregnancy, rosette.

ABBREVIATION : IE, Plasmodium falciparum-infected erythrocyte.

I $\mathrm{n}$ areas in which Plasmodium falciparum malaria is endemic, placental malaria is frequent and associated with low birth weight of the baby, a major cause of neonatal morbidity, thus posing a public health problem (for review, see Brabin, 1991 and Menendez, 1995). In the placenta, most of infected erythrocytes (IE) contain mature stages of the parasite, while IEs from

\footnotetext{
* Organisation de Coordination pour la Lutte contre les Endémies en Afrique Centrale (OCEAC), PB288, Yaounde, Cameroon.

** Institut Français de Recherche Scientifique pour le Développement en Coopération (ORSTOM).

${ }^{* * *}$ Institut National de la Santé et de la Recherche Médicale U13/Institut de Médecine et d'Épidémiologie Africaine, Hôpital BichatClaude-Bernard, 46, rue Henri-Huchard, 75018 Paris, France.

**** Present address: Philippe Deloron, Unité de Parasitologie Médicale, Centre International de Recherche Médicale de Franceville, BP 769, Franceville, Gabon.

Correspondence: B. Maubert IMEA/INSERM U13, Hôpital Bichat, 46, rue Henri-Huchard, 75018 Paris, France. Tel.: (33) 0140256365 Fax: (33) 01402563 51. e-mail: maubert@bichat.inserm.fr.
}

Résumé : PLASMODIUM FALCIPARUM NE FORME PAS DE ROSETTES CHEZ LES FEMMES ENCEINTES CAMEROUNAISES

Chez la femme enceinte en zone d'endémie malarique, le placenta séquestre les hématies parasitées par les stades matures de Plasmodium falciparum, ce qui entraîne un faible poids de naissance. Il a été suggéré que la cytoadhérence au syncytiotrophoblaste pouvait être impliquée dans la séquestration placentaire, mais le rôle des autres mécanismes de séquestration n'a pas été étudié. Nous avons recherché si la séquestration pouvait résulter de la formation de rosettes des hématies parasitées avec des hématies non parasitées. Nous avons mesuré la capacité à former des rosettes d'isolats de P. falciparum provenant du sang placentaire et du sang périphérique de femmes enceintes, ainsi que du sang périphérique de sujets non enceintes. Chez les sujets non enceintes, la fréquence et l'intensité de la formation de rosettes étaient conformes aux valeurs rapportées dans d'autres études, alors que, hormis un cas, les parasites des femmes enceintes ne formaient pas de rosettes. En conclusion, la séquestration placentaire des hématies parasitées par $P$. falciparum ne peut pas résulter de la formation de rosettes et le manque de capacité à former des rosettes est une nouvelle caractéristique des isolats des femmes enceintes.

MOTS CLÉS : paludisme, Plasmodium falciparum, humain, placenta, grossesse, rosette.

the peripheral blood of the same woman contains only young stages (Garnham, 1938). The involvement of cytoadherence as a mechanism for the sequestration of IEs in the placenta has been reported (Fried \& Duffy, 1996; Maubert et al., 1997), but other potential mechanisms have not been assessed. Rosettes (binding of at least two uninfected erythrocytes to an infected erythrocyte) are large cellular structures that facilitate the sequestration of IEs in microvasculature ex vivo (Kaul et al., 1991). We investigated whether malaria parasites from pregnant women could form rosettes, that could be trapped in the placental intervillous spaces. For this purpose, we compared the rosetting ability of parasites from pregnant and non pregnant subjects.

\section{METHODS AND RESULTS}

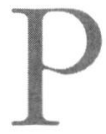

arasites from non pregnant subjects were collected from nine women and five men attending at the Messa dispensary, Yaounde, 
Cameroon. They presented with acute but uncomplicated $P$. falciparum malaria, a peripheral parasitaemia higher than $0.2 \%$, and were $22.2 \pm 6.6$ years old $(m \pm \mathrm{SD})$. Blood samples were drawn and parasites were cryoconserved in liquid nitrogen. Before the assay, samples were thawed and cultured for less than one cycle to pigmented stages (late trophozoites to young schizonts) according to the standard method (Trager \& Jensen, 1976). Among those 14 isolates, parasites from 12 showed mature stages within the first life cycle, and rosetting assay was performed using the standard procedure (Carlson \& Wahlgren, 1992). Briefly, $50 \mu \mathrm{l}$ of the parasite culture was mixed with $50 \mu \mathrm{l}$ of a $0.01 \%$ acridine orange solution. $10 \mu \mathrm{l}$ of the suspension were distributed under a $22 \times 22 \mathrm{~mm}$ coverslip and at least 200 IEs were examined under fluorescence microscopy using $\times 500$ magnification. The number of rosettes (i. e. IEs that bound at least two uninfected erythrocytes) was determined. Eight out of the 12 samples studied formed rosettes, the percent of IEs forming rosettes being: 1, 1, 1, 5.5, 6.5, 7.5, 14.5, and 17.5. These figures are in line with other reports (Hasler et al., 1990; Wahlgren et al., 1990), and the rosetting ability was not related to sex.

We assessed rosette formation in placental blood from parasitized placentas collected after delivery in two maternity hospitals (Nkolndongo and Etoudi) of Yaounde. Their age was similar to the one of non pregnant subjects $(21.5 \pm 5.6$ years $)$. An incision was made on the maternal face of the placenta and a drop of placental blood was diluted to a $5 \%$ hematocrit in $P$. falciparum culture medium containing acridine orange. Rosetting rate was assessed as above. None of the 23 infected placental blood studied presented with rosettes.

As the absence of rosettes in placental blood may be related to alteration of the IEs during labor, we studied parasites from the peripheral blood of pregnant women. Twenty five women (age: $22.8 \pm 4.6$ ) presenting with a blood parasites were bled within one hour after delivery and parasites were cryoconserved. Rosetting assay was performed as mentioned for non pregnant subjects. After in vitro culture, 16 samples showed mature parasites and at least $0.2 \%$ parasite density. Seven were the peripheral counterpart of studied placental parasites and nine were from other women. Only one formed rosettes and the percentage of rosette-forming IEs was low (2\%).

\section{DISCUSSION}

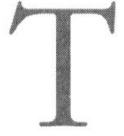

he frequency of rosetting was higher in parasites from non-pregnant $(8 / 12)$ than in peripheral blood from pregnant subjects $(1 / 16)$
(Fisher's exact test $p=0.001$ ), and than in placental blood (0/23) (Fisher's exact test $p<0.0001$ ). As rosetting assay with parasites from peripheral blood was performed in a medium free of immune serum, the difference in rosetting ability cannot result from a difference in antibodies against rosettes.

In non-pregnant host, rosetting facilitates the sequestration of parasites ex vivo (Kaul et al., 1991). However the implication of rosetting in human pathology remains uncertain as studies conducted in Gambia (Carlson, 1993) and in Kenia (Rowe et al., 1995) found an association between rosetting and the development of severe or cerebral malaria, while no such relationship was found in a larger study carried out in Papua New Guinea (Al-Yaman et al., 1995). Although pregnant women are at increased risk for malaria (Diagne et al., 1997), our data demonstrate that rosetting is not involved in pregnancy-related malaria morbidity which has to be explained by other mechanisms. Parasites from pregnant and non pregnant women were recently been shown to differ in their cytoadherence phenotype (Fried \& Duffy, 1996). Our data show that the lack of rosetting ability is another feature of parasites from pregnant women and that rosetting cannot contribute to parasite concentration in the placenta.

\section{ACKNOWLEDGEMENTS}

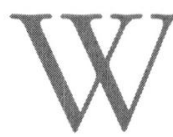

e are indebted to Anne Daban and the staff of the maternity clinics of Nkolndongo and Etoudi, and especially to Odette Nkouo and Sister Anne-Philippe. This work was supported by Institut National de la Santé et de la Recherche Médicale (INSERM) and Institut Français de Recherche Scientifique pour le Développement en Coopération (ORSTOM) and Organisation de Coordination pour la Lutte contre les Endémies en Afrique Centrale (OCEAC). Bertrand Maubert was a recipient of a fellowship of the French Ministère de l'Éducation Nationale, de l'Enseignement Supérieur et de la Recherche.

\section{REFERENCES}

Al-Yaman F., Genton B., Mokela D., Raiko A., Kati S., Rogerson S., REEDER J. \& AlPers M. Human cerebral malaria: lack of significant association between erythrocyte rosetting and disease severity. Transactions of the Royal Society of Tropical Medicine and Hygiene, 1995, 89, 55-58.

BRABIN B.J. The risk and severity of malaria in pregnant women. Applied Field Research in Malaria Reports $\mathrm{N}^{\circ} 1$ TDR/FIELDMAL/1. Special Programme for Research and Training in Tropical Diseases, 1991, p. 33. 
CARLSON J. Erythrocyte rosetting in Plasmodium falciparum malaria, with special reference to the pathogenesis of cerebral malaria. Doctoral Thesis, Uppsala University, Sweden, 1993.

Carlson J. \& Wahlgren M. Plasmodium falciparum erythrocyte rosetting is mediated by promiscuous lectin-like interactions. Journal of Experimental Medicine, 1992, 176, 1311-1317.

Diagne N., Rogier C., Cisse B. \& Trape J.F. Incidence of clinical malaria in pregnant women exposed to intense perennial transmission. Transactions of the Royal Society of Tropical Medicine and Hygiene, 1997, 91, 166-170.

Fried M. \& DuFfy P.E. Adherence of Plasmodium falciparum to chondroitin sulfate A in the human placenta. Science, 1996, 272, 1502-1504.

Garnham P.C.C. The placenta in malaria with special reference to reticulo-endothelial immunity. Transactions of the Royal Society of Tropical Medicine and Hygiene, 1938, 32, 13-48.

Hasler T., Handunnetti S.H., Aguiar J.C., van SchravendijK M.R., Greenwood B.M., Lallinger G., Cegielski P. \& HowARD R.J. In vitro rosetting, cytoadherence and microagglutination of Plasmodium falciparum-infected erythrocytes from Gambian and Tanzanian patients. Blood, 1990, 76, 1845-1852.

Kaul D.K., Roth Jr. E.F., Nagel R.L., Howard R.J. \& HanDUNNETTI S.M. Rosetting of Plasmodium falciparum-infected red cells with uninfected red cells enhances vasoocclusion in an ex vivo microvascular system. Blood, 1991, 78, 812819.

Maubert B., Guilbert L.J. \& Deloron P. Plasmodium falciparum-infected erythrocyte sequestration in the human placenta: cytoadherence mechanisms involving intercellular adhesion molecule- 1 and chondroitin-4-sulfate as syncytiotrophoblast receptors. Infection and Immunity, 1997, 65, 1251-1257.

MENENDEZ C. Malaria during pregnancy: a priority area of malaria research and control. Parasitology Today, 1995, 11, 178-193.

Rowe A., Obeiro J., Newbold C.I. \& Marsh K. Plasmodium falciparum rosetting is associated with malaria severity in Kenya. Infection and Immunity, 1995, 63, 2323-2326.

Trager W. \& Jensen J.B. Human malaria parasites in continuous culture. Science, 1976, 193, 673-675.

Wahlgren M., Carlson J., Ruangjirachuporn W., Conway D., Helmby H., Martinez A., Patarroyo M.E. \& Riley E. Geographical distribution of Plamodium falciparum erythrocyte rosetting and frequency of rosetting antibodies in human sera. American Journal of Tropical Medicine and Hygiene, 1990, 43, 333-338.

Reçu le 17 février 1998 Accepté le 25 avril 1998 